\title{
Bulky DNA adducts, 4-aminobiphenyl-haemoglobin adducts and diet in the European Prospective Investigation into Cancer and Nutrition (EPIC) prospective study
}

Marco Peluso $^{1}$, Luisa Airoldi ${ }^{2}$, Armelle Munnia ${ }^{1}$, Alessandro Colombi ${ }^{2}$, Fabrizio Veglia ${ }^{3}$, Herman Autrup ${ }^{4}$, Alison Dunning ${ }^{5}$, Seymour Garte ${ }^{6}$, Emmanuelle Gormally ${ }^{7}$, Christian Malaveille ${ }^{7}$, Giuseppe Matullo ${ }^{3}$, Kim Overvad $^{8}$, Ole Raaschou-Nielsen ${ }^{9}$, Francoise Clavel-Chapelon ${ }^{10}$, Jacob Linseisen ${ }^{11}$, Heiner Boeing ${ }^{12}$, Antonia Trichopoulou ${ }^{13}$, Domenico Palli ${ }^{14}$, Vittorio $\mathrm{Krogh}^{15}$, Rosario Tumino ${ }^{16}$, Salvatore Panico ${ }^{17}$, Bas H. Bueno-De-Mesquita ${ }^{18}$, Petra H. Peeters ${ }^{19}$, Merethe Kumle ${ }^{20}$, Antonio Agudo ${ }^{21}$, Carmen Martinez ${ }^{22}$, Miren Dorronsoro $^{23}$, Aurelio Barricarte ${ }^{24}$, Marì Jose Tormo ${ }^{25}$, José Ramón Quiros ${ }^{26}$, Goran Berglund ${ }^{27}$, Bengt Jarvholm ${ }^{28}$, Nicholas E. Day ${ }^{29}$, Timothy J. Key ${ }^{30}$, Rodolfo Saracci ${ }^{31}$, Rudolf Kaaks ${ }^{32}$, Elio Riboli ${ }^{33}$, Shelia Bingham ${ }^{29}$ and Paolo Vineis ${ }^{34,35 *}$

${ }^{1}$ Cancer Risk Factor Branch, Analytical and Biomolecular Cytology Unit, CSPO-Scientific Institute of Tuscany, Florence, Italy

${ }^{2}$ Istituto di Ricerche Farmacologiche Mario Negri, Milan, Italy

${ }^{3}$ ISI Foundation, Turin, Italy

${ }^{4}$ Department of Environmental and Occupational Medicine, Aarhus, Denmark

${ }^{5}$ Department of Oncology, University of Cambridge, Cambridge, UK

${ }^{6}$ Genetics Research Institute, Milan, Italy

${ }^{7}$ International Agency for Research on Cancer, Lyon, France

${ }^{8}$ Department of Clinical Epidemiology, Aalborg Hospital, Aarhus University Hospital, Aalborg, Denmark

${ }^{9}$ Institute of Cancer Epidemiology, Danish Cancer Society, Copenhagen, Denmark

${ }^{10}$ INSERM (Institut National de la Santé et de la Recherche Médicale), ERI 20, EA 4045, and Institut Gustave Roussy, Villejuif, F-94805, France

${ }^{11}$ Division of Clinical Epidemiology, Deutsches Krebsforschungszentrum, Heidelberg, Germany

${ }^{12}$ German Institute of Human Nutrition, Potsdam-Rehbücke, Germany

${ }^{13}$ Department of Hygiene and Epidemiology, Medical School, University of Athens, Athens, Greece

${ }^{14}$ Molecular and Nutritional Epidemiology Unit, CSPO-Scientific Institute of Cancer Prevention Tuscany Region, Florence, Italy

${ }^{15}$ Department of Epidemiology, National Cancer Institute, Milan, Italy

${ }^{16}$ Cancer Registry, Azienda Ospedaliera 'Civile MP Arezzo', Ragusa, Italy

${ }^{17}$ Dipartimento di Medicina Clinica e Sperimentale, Università Federico II, Naples, Italy

${ }^{18}$ Centre for Nutrition and Health, National Institute for Public Health and the Environment, Bilthoven, The Netherlands

${ }^{19}$ Julius Center for Health Sciences and Primary Care, University Medical Center, Utrecht, The Netherlands

${ }^{20}$ Institute of Community Medicine, University of Tromso, Tromso, Norway

${ }^{21}$ Department of Epidemiology, Catalan Institute of Oncology, Barcelona, Spain

${ }^{22}$ Andalusian School of Public Health, Granada, Spain

${ }^{23}$ Department of Public Health of Guipuzkoa, San Sebastian, Spain

${ }^{24}$ Public Health Institute, Navarra, Spain

${ }^{25}$ Epidemiology Department, Murcia Health Council, Murcia, Spain

${ }^{26}$ Dirección General de Salud Pública, Consejería de Salud y Servicios Sanitarios Asturias, Oviedo, Spain

${ }^{27}$ Malmö Diet and Cancer Study, Lund University, Malmö, Sweden

${ }^{28}$ Department of Nutritional Research, University of Umeå, Umeå, Sweden

${ }^{29}$ MRC Dunn Human Nutrition Unit, Cambridge University, UK

${ }^{30}$ Cancer Research UK Epidemiology Unit, University of Oxford, Oxford, UK

${ }^{31}$ IFC National Research Council, Pisa, Italy

${ }^{32}$ Division of Epidemiology, DKFZ Heidelberg, Germany 


\author{
${ }^{33}$ Imperial College London, London, UK \\ ${ }^{34}$ University of Turin, Turin, Italy \\ ${ }^{35}$ Department of Epidemiology and Public Health, Imperial College of Science, Technology and Medicine, Norfolk Place, London \\ W2 $1 P G, U K$
}

(Received 20 June 2007 - Revised 12 December 2007 - Accepted 14 December 2007 - First published online 14 February 2008)

In contrast to some extensively examined food mutagens, for example, aflatoxins, $N$-nitrosamines and heterocyclic amines, some other food contaminants, in particular polycyclic aromatic hydrocarbons (PAH) and other aromatic compounds, have received less attention. Therefore, exploring the relationships between dietary habits and the levels of biomarkers related to exposure to aromatic compounds is highly relevant. We have investigated in the European Prospective Investigation into Cancer and Nutrition (EPIC) cohort the association between dietary items (food groups and nutrients) and aromatic DNA adducts and 4-aminobiphenyl-Hb adducts. Both types of adducts are biomarkers of carcinogen exposure and possibly of cancer risk, and were measured, respectively, in leucocytes and erythrocytes of 1086 (DNA adducts) and 190 (Hb adducts) non-smokers. An inverse, statistically significant, association has been found between DNA adduct levels and dietary fibre intake $(P=0 \cdot 02)$, vitamin $\mathrm{E}$ $(P=0.04)$ and alcohol $(P=0.03)$ but not with other nutrients or food groups. Also, an inverse association between fibre and fruit intake, and BMI and 4-aminobiphenyl-Hb adducts $(P=0.03,0.04$, and 0.03 respectively) was observed. After multivariate regression analysis these inverse correlations remained statistically significant, except for the correlation adducts $v$. fruit intake. The present study suggests that fibre intake in the usual range can modify the level of DNA or $\mathrm{Hb}$ aromatic adducts, but such role seems to be quantitatively modest. Fibres could reduce the formation of DNA adducts in different manners, by diluting potential food mutagens and carcinogens in the gastrointestinal tract, by speeding their transit through the colon and by binding carcinogenic substances.

DNA adducts: Haemoglobin adducts: Non-smokers: Fibre intake: Air pollution

Most cancers result from a complex interaction of environmental factors, genetic susceptibility and lifestyle factors ${ }^{(1)}$. Diet is an important component of lifestyle, and its role in the maintenance of good health and as a determinant of different types of chronic diseases, including cancer, has been extensively studied ${ }^{(1)}$. Diets that emphasise the consumption of whole-grain foods, legumes, vegetables and fresh fruits and that limit animal fat have been associated with decreased cancer risk ${ }^{(1-4)}$. Dietary patterns with high intake of fibres have also emerged as possible important preventive factors for cancer ${ }^{(1-4)}$. On the other hand, diet can contribute to cancer risk through the consumption of food mutagens ${ }^{(5)}$, contained in contaminated foods or generated by frying, toasting and broiling of certain foods ${ }^{(6)}$. In contrast to some extensively examined food mutagens, for example, aflatoxins, $\mathrm{N}$-nitrosamines and heterocyclic amines, some other food contaminants, in particular polycyclic aromatic hydrocarbons (PAH) and other aromatic compounds, have received less attention. PAH may occur in fried and charcoal-grilled meat or in the food chain as a result of environmental pollution ${ }^{(5-7)}$. PAH are an important class of carcinogens, capable of inducing the formation of DNA adducts leading to DNA damage after metabolic activation ${ }^{(8)}$. Targets for PAH carcinogenicity are several organs, including lung and bladder ${ }^{(8)}$. Some evidence has been also reported for an association between dietary $\mathrm{PAH}$ and colon cancer or adenomas ${ }^{(9,10)}$. In addition, increased levels of bulky DNA adducts have been detected in the colon mucosa of colon cancer patients and in early stages of colon carcinogenesis ${ }^{(11,12)}$.

4-Aminobiphenyl (4-ABP) is a human bladder carcinogen formed during tobacco combustion, and detected both in main- and side-stream smoke ${ }^{(13,14)}$. Although tobacco smoke is the main source of 4-ABP human exposure, additional sources are known that may contribute to the total burden of human exposure, including diesel exhaust and heated cooking oils $^{(15-17)}$. Upon metabolic activation, 4-ABP reactive species bind covalently to DNA to form adducts, that, if not repaired, may start the process of carcinogenesis. 4-ABP reactive species in the body also bind to other macromolecules, including $\mathrm{Hb}^{(18)}$.

Exploring the relationships between dietary habits and the levels of biomarkers related to exposure to aromatic compounds is highly relevant. Food can be the source of mutagenic aromatic compounds, but it can also exert a protective effect over the genotoxic potential of certain compounds. In particular, an inverse association between fruit and/or vegetable intake and carcinogen-DNA adducts has been recently reported, including observations in the European Prospective Investigation into Cancer and Nutrition (EPIC) study (limited to the Italian branch) ${ }^{(19-21)}$.

In the present study, we have investigated in the EPIC cohort the association between dietary items and bulky DNA adducts and 4-ABP-Hb adducts measured, respectively, in leucocytes and erythrocytes of non-smokers.

\section{Subjects and methods \\ Selection of subjects and collection of specimens}

EPIC is a multicentre European study, coordinated by the International Agency for Research on Cancer, Lyon, in which more than 500000 healthy volunteers were recruited in ten European countries (France, Denmark, Germany, Greece, Italy, The Netherlands, Norway, Spain, Sweden, UK) corresponding to twenty-three recruitment centres ${ }^{(22)}$. The cohort includes subjects of both sexes, mostly in the age range 35-74 years at recruitment. Recruitment took place between 1993 and 1998. Detailed dietary and lifestyle 
histories collected mainly through self-administered questionnaires, plus a $24 \mathrm{~h}$ dietary recall through individual-to individual interview (in a $10 \%$ sample), anthropometric measurements and a $30-40 \mathrm{ml}$ blood sample are available. All questionnaire information is available in a computerised format. Signed informed consent forms were collected from all participants (except a sub-group of the Oxford cohort who gave consent on postal questionnaires).

GenAir is a case-control study nested within the EPIC cohort, aiming at studying the relationship between select cancer types and air pollution or environmental tobacco smoke. Cases are subjects with bladder, lung, oral, pharyngeal, or laryngeal cancers or leukaemia, all newly diagnosed after recruitment. Only non-smokers or ex-smokers since at least 10 years were eligible for the GenAir sub-study. Three controls per case were matched for exposure assessment and the analysis of questionnaire data, and two controls per case for laboratory analyses. Matching criteria were sex, age $( \pm 5$ years), smoking status (never or former smoker), country of recruitment, and follow-up time ${ }^{(23)}$.

GenAir has been approved by the Ethical Committee of the International Agency for Research on Cancer, and by the local Ethical Committees of the twenty-three centres.

The present study focuses on dietary determinants of DNA or $\mathrm{Hb}$ adducts in a healthy population, therefore the analysis is limited to the control population of GenAir.

Overall, 2977 controls met the protocol criteria. Of these subjects, 1564 had blood samples. Blood samples of controls for centres which have released an ethical approval have been sent to laboratories for investigation. The Malmö centre has decided not to allow the use of its blood samples, while Umeå participated only with erythrocytes. Therefore, DNA samples were available and successfully analysed among 1086 control subjects. Levels of 4-ABP-Hb adducts were analysed in $190 \mathrm{Hb}$ samples.

\section{Dietary variables}

Dietary information on the frequency of consumption of more than 120 foods and drinks has been obtained by dietary questionnaires developed and validated in a pilot phase in each participating country. At enrolment, weight, height, and waist and hip circumferences have been measured for each participant. Detailed information has been collected on reproductive history, physical activity, smoking and alcohol drinking history, medical history, occupation, education level and other socio-economic variables.

Here we consider dietary variables that can be associated with levels of DNA adducts as suggested by previous investigations: intake of fruit, legumes, vegetables, alcohol, total energy, fibres, vitamins $\mathrm{C}$ and $\mathrm{E}, \beta$-carotene (as estimated from food intake) and (only in four centres) folic acid (nine dietary items were analysed plus alcohol and BMI). Also BMI was considered as a potential predictor of DNA and $\mathrm{Hb}$ adducts. For details on the methods, see Peluso et al. and Airoldi et al. ${ }^{(23,24)}$. Also exposure levels for selected air pollutants $\left(\mathrm{NO}_{2}, \mathrm{PM} 10\right.$ (particulate matter of $10 \mu \mathrm{m}$ or less), $\mathrm{SO}_{2}$, ozone) have been estimated in GenAir; details on the estimation methods and results for lung cancer are given elsewhere ${ }^{(23,25)}$.

\section{$\left[{ }^{32} P\right] D N A$ post-labelling technique}

DNA was extracted and purified from the buffy coat using a method requiring enzymic digestion of RNA and proteins followed by phenol-chloroform extraction, with the exception of the Danish samples that were extracted and purified from lymphocytes using a technique based on a salting-out procedure $^{(23)}$. Coded DNA was stored at $-80^{\circ} \mathrm{C}$ until laboratory analysis. Bulky DNA adducts were analysed blindly using the nuclease P1 modification of the $\left[{ }^{32} \mathrm{P}\right]$ post-labelling assay ${ }^{(23)}$ in the laboratory directed by M. P. Details of the technique have been previously reported ${ }^{(23)}$.

\section{4-Aminobiphenyl-Hb extraction and quantitative analysis}

Packed erythrocytes were selected at the International Agency for Research on Cancer and sent frozen to the Mario Negri Institute where they were stored at $-80^{\circ} \mathrm{C}$ until analysis. $4-\mathrm{ABP}-\mathrm{Hb}$ adducts were determined by parent arylamine after alkaline hydrolysis of the adducted $\mathrm{Hb}$, and quantified by high-resolution GC-negative ion chemical ionisation-MS with selective ion monitoring as its pentafluoroacyl derivative, using the stable-isotope dilution technique. Details of the methodology used have been previously described ${ }^{(24)}$.

\section{Statistical analysis}

We have computed correlation coefficients, and regression coefficients in multivariate regression models. The models included age, sex, country, smoking (never/ex-smoker), educational level (in six categories) and BMI (continuous). In addition the intake of fibres, fruit, legumes, vegetables, and energy, and estimates of the intake of vitamins $\mathrm{C}$ and $\mathrm{E}$, and $\beta$-carotene were considered (all continuous variables). We also considered estimated intake of folic acid (available in four centres), and four air pollutants. Descriptive statistics and frequency histograms indicated that adduct levels were not normally distributed, because of a large number of adduct values that were below the detection limit of the method. For levels of DNA adducts below the instrumental detection limit of 0.1 we have imputed the value of $0 \cdot 1$. Hb samples with undetectable 4-ABP adduct levels $(\leq 20 \mathrm{pg} / \mathrm{g} \mathrm{Hb})$ were considered as having half the detection limit of the method (i.e. $10 \mathrm{pg} / \mathrm{g} \mathrm{Hb}$ ). Since only nine selected dietary items (based on previous hypotheses) plus alcohol and BMI have been selected we did not apply Bonferroni correction for multiple comparisons.

We used adducts as a continuous variable with and without log-transformation.

\section{Results}

Table 1 shows the mean levels and standard deviations of bulky DNA adducts and $4-\mathrm{ABP}-\mathrm{Hb}$ adducts, by relevant demographic variables. As it has already been stressed ${ }^{(23)}$, one limitation of the adduct technology is the large inter-individual variability (large standard deviations). Table 2 shows the mean levels of DNA and $\mathrm{Hb}$ adducts below and above the median levels of relevant dietary or anthropometric variables. For $\mathrm{Hb}$ adducts there were no appreciable differences for any dietary variable except for fibres, fruit and BMI. 
Table 1. DNA and 4-aminobiphenyl (4-ABP)-Hb adducts, by demographic variables and smoking

(Mean values and standard deviations)

\begin{tabular}{|c|c|c|c|c|}
\hline & \multicolumn{2}{|c|}{$\begin{array}{l}\text { DNA adducts } \\
\left(\times 10^{8}\right)\end{array}$} & \multicolumn{2}{|c|}{$\begin{array}{l}\text { 4-ABP adducts } \\
\text { (pg/g Hb) }\end{array}$} \\
\hline & Mean & SD & Mean & SD \\
\hline Subjects $(n)$ & \multicolumn{2}{|c|}{1086} & \multicolumn{2}{|c|}{190} \\
\hline Sex & & & & \\
\hline Women & 0.71 & 0.55 & $40 \cdot 0$ & $66 \cdot 8$ \\
\hline Men & 0.68 & 0.54 & 29.4 & $31 \cdot 8$ \\
\hline \multicolumn{5}{|l|}{ Age (years) } \\
\hline$<55$ & 0.69 & 0.61 & 35.5 & 55.5 \\
\hline $55-64$ & 0.68 & 0.53 & $35 \cdot 6$ & $56 \cdot 2$ \\
\hline $65+$ & 0.71 & 0.52 & $30 \cdot 6$ & 37.6 \\
\hline \multicolumn{5}{|l|}{ Smoking status } \\
\hline Never smoker & 0.71 & 0.57 & 34.5 & $59 \cdot 0$ \\
\hline Former smoker & 0.69 & 0.52 & $33 \cdot 1$ & 38.0 \\
\hline
\end{tabular}

The distribution was skewed for both types of adducts, but particularly for $\mathrm{Hb}$ adducts, and the analyses were repeated after log-transformation, with only slight changes. Both types of adducts, but particularly $\mathrm{Hb}$ adducts, show lower mean levels for higher fibre intakes. Table 3 shows correlation coefficients between adduct levels and selected dietary

Table 2. Mean levels of bulky DNA adducts or 4-aminobiphenyl (4-ABP)- $\mathrm{Hb}$ adducts below and above the median level of fibre intake and other selected dietary variables and $\mathrm{BMI}$ (one or two missing values depending on item)

(Mean values with their standard errors)

\begin{tabular}{|c|c|c|c|c|}
\hline & $n$ & Mean & $\mathrm{SE}$ & $P^{*}$ \\
\hline \multicolumn{5}{|l|}{ DNA adducts } \\
\hline \multicolumn{5}{|l|}{ Fibres } \\
\hline Below median & 545 & 0.73 & 0.025 & \multirow[t]{2}{*}{0.025} \\
\hline Above median & 539 & 0.65 & 0.020 & \\
\hline \multicolumn{5}{|l|}{ Fruit } \\
\hline Below median & 528 & 0.67 & 0.023 & \multirow[t]{2}{*}{0.15} \\
\hline Above median & 557 & 0.72 & 0.023 & \\
\hline \multicolumn{5}{|l|}{ Vegetables } \\
\hline Below median & 548 & 0.68 & 0.024 & \multirow[t]{2}{*}{0.43} \\
\hline Above median & 537 & 0.71 & 0.023 & \\
\hline \multicolumn{5}{|l|}{ Legumes } \\
\hline Below median & 521 & 0.66 & 0.021 & \multirow[t]{2}{*}{0.04} \\
\hline Above median & 564 & 0.73 & 0.025 & \\
\hline \multicolumn{5}{|l|}{ Alcohol } \\
\hline Below median & 500 & 0.73 & 0.024 & \multirow[t]{2}{*}{0.04} \\
\hline Above median & 584 & 0.66 & 0.022 & \\
\hline \multicolumn{5}{|l|}{ BMI } \\
\hline Below median & 552 & 0.70 & 0.024 & \multirow[t]{2}{*}{0.78} \\
\hline Above median & 533 & 0.69 & 0.023 & \\
\hline \multicolumn{5}{|l|}{ Energy intake } \\
\hline Below median & 522 & 0.72 & 0.025 & \multirow[t]{2}{*}{0.12} \\
\hline Above median & 563 & 0.67 & 0.022 & \\
\hline \multicolumn{5}{|l|}{ 4-ABP-Hb adducts } \\
\hline Fibres & & & & \\
\hline Below median & 89 & 40.46 & 6.77 & \multirow[t]{2}{*}{0.07} \\
\hline Above median & 93 & 27.57 & 3.62 & \\
\hline \multicolumn{5}{|l|}{ Fruit } \\
\hline Below median & 92 & 39.76 & 5.76 & \multirow[t]{2}{*}{0.11} \\
\hline Above median & 96 & 28.84 & 4.68 & \\
\hline \multicolumn{5}{|l|}{ BMI } \\
\hline Below median & 96 & 38.98 & 6.56 & \multirow[t]{2}{*}{0.14} \\
\hline Above median & 92 & 29.15 & 3.21 & \\
\hline
\end{tabular}

* Based on $t$ test.
Table 3. Correlation coefficients between selected dietary variables and adduct levels (Pearson correlation coefficients and $P$ values)

\begin{tabular}{lcc}
\hline & Pearson correlation coefficients & $P$ \\
\hline DNA adducts & & \\
Vegetables & -0.029 & 0.32 \\
Legumes & 0.010 & 0.73 \\
Fruit & 0.008 & 0.78 \\
Fibres & -0.067 & 0.02 \\
Vitamin C & -0.009 & 0.74 \\
Vitamin E & -0.061 & 0.04 \\
$\beta$-Carotene & -0.040 & 0.14 \\
Folate & -0.06 & 0.17 \\
Alcohol & -0.07 & 0.03 \\
BMl & -0.04 & 0.22 \\
Energy & -0.060 & 0.05 \\
4-Aminobiphenyl-Hb adducts & & \\
Vegetables & -0.11 & 0.12 \\
Legumes & -0.017 & 0.81 \\
Fruit & -0.15 & 0.04 \\
Fibres & -0.15 & 0.03 \\
Vitamin C & -0.08 & 0.25 \\
Vitamin E & -0.08 & 0.27 \\
$\beta$-Carotene & -0.05 & 0.45 \\
Folate & -0.09 & 0.33 \\
Alcohol & 0.01 & 0.85 \\
BMl & -0.16 & 0.03 \\
Energy & -0.08 & 0.23 \\
\hline & & \\
\hline & & \\
& & \\
& & \\
\hline
\end{tabular}

variables. Statistically significant associations are evident for DNA adducts and the intake of fibres (correlation coefficient $-0.067 ; P=0.02)$ and for $\mathrm{Hb}$ adducts and the intake of fibres (correlation coefficient $-0.15 ; P=0.03$ ) and fruit (correlation coefficient $-0.15 ; \quad P=0 \cdot 04)$. No association was found between either adduct type and folate intake.

Table 4 shows multivariate regression models including age, sex, smoking status and country. Based on results shown in Table 3, alcohol and energy were added to the DNA adducts model, and BMI to the $4-\mathrm{ABP}-\mathrm{Hb}$ adducts model. A statistically significant association is shown between fibres and DNA adducts. The association with fibre intake became slightly weaker when ozone, an air pollutant, was included into the model. Other air pollutants (PM10, $\mathrm{SO}_{2}$, $\mathrm{NO}_{2}$ ) had no clear effect on adduct levels; details are given elsewhere ${ }^{(25)}$. Also, the association with fibres was apparently present only in former smokers. An association between fibre intake and 4-ABP-Hb adducts is suggestive but falls short of significance. An association between $\mathrm{BMI}$ and $\mathrm{Hb}$ adducts is also suggested but disappeared after log-transformation of the adduct variable (Table 4).

\section{Discussion}

In the EPIC investigation we have recently examined prospectively the ability of bulky DNA adducts to predict cancer and we have found that leucocyte DNA adducts may predict lung cancer risk among never and former smokers ${ }^{(24)}$. In addition we have provided evidence that, particularly among women, elevated $4-\mathrm{ABP}-\mathrm{Hb}$ adducts may help identify subjects at higher risk of environmental tobacco smoke-related cancers ${ }^{(24)}$.

In the present study, we have investigated the association between dietary items and bulky DNA adducts and 4$\mathrm{ABP}-\mathrm{Hb}$ adducts measured, respectively, in leucocytes and 
Table 4. Multivariate regression models*

\begin{tabular}{lcrl}
\hline Independent variables & Parameter estimate & $t$ & $P$ \\
\hline DNA adducts & & & \\
Age (continuous) & 0.000 & 0.17 & 0.857 \\
Sex & -0.01 & -0.43 & 0.67 \\
Country & - & -2.92 & 0.003 \\
Smoking status $\dagger$ & -0.03 & -0.74 & 0.46 \\
Alcohol (g/d) & -0.002 & -1.83 & 0.07 \\
Energy (MET) & 0.000 & 0.49 & 0.62 \\
Fibres (g/d) & -0.006 & -2.28 & $0.02 \ddagger$ \\
After inclusion of ozone & & & \\
Fibres & -0.0054 & -1.97 & 0.050 \\
Ozone ( $\mu$ g/m ${ }^{3}$ ) & 0.007 & 1.95 & 0.051 \\
After stratification by smoking habits & & & \\
Fibres (non-smokers) & 0.002 & -0.55 & 0.57 \\
Fibres (former smokers) & -0.009 & -2.39 & $0.02 \S$ \\
4-BP-Hb adducts & & & \\
Age (continuous) & -0.48 & -1.06 & 0.27 \\
Sex & 11.3 & 1.41 & 0.16 \\
Country & - & 1.19 & 0.23 \\
Smoking status $\dagger$ & 1.07 & 0.13 & 0.90 \\
BMl & -2.18 & -2.59 & $0.01 \|$ \\
Fibres & 0.94 & -2.21 & $0.03 ף$ \\
\hline
\end{tabular}

MET, metabolic equivalent values; $A B P$, aminobiphenyl.

* The dependent variable is DNA adducts or 4-ABP-Hb adducts. All independent variables except sex, country and smoking (never or ex-smoker) are continuous. Ozone was measured in 1990-98.

†Former $v$. never smokers.

After log-transformation of DNA adducts, $t=-2.02(P=0.04)$

$\S$ After log-transformation of DNA adducts, $t=-2.14(P=0.03)$.

\| After log-transformation of 4-ABP-Hb adducts, $t=-1.46(P=0.15)$.

ๆ After log-transformation of 4-ABP-Hb adducts, $t=-1.95(P=0.05)$

erythrocytes of non-smokers. The rationale came from the presence of mutagenic PAH and aromatic compounds in food, and from previous observations relating high intakes of fruit and vegetables to decreased levels of adducts. No dietary item was associated with the levels of aromatic DNA or $\mathrm{Hb}$ adducts, except the intake of fibres, independently of levels of vitamins or folate intake.

When exposure to an air pollutant, ozone, was included into the regression model, the role of fibres was slightly weakened. Also, the association with fibres was present only in former smokers, an observation that suggests complex interactions between exposure to carcinogens and to protective compounds. In a study in healthy volunteers we have found that diet can have an important effect on the induction of DNA repair genes ${ }^{(26)}$. One can speculate the expression of DNA repair genes is increased by fibre intake or correlates of fibre intake (such as polyphenols), particularly in subjects who have had extensive DNA damage in the past such as exsmokers.

Whereas the effect of fruit and vegetable intake on the formation of adducts of different carcinogens has been widely investigated, studies on the effects of dietary fibres are scanty. The relationship of fruit and vegetable consumption to bulky DNA-adduct formation was already examined by us in a case-control study on bladder cancer $^{(19)}$. The level of leucocyte DNA adducts was shown to decrease with increasing levels of vegetable consumption in controls. In addition, the association between case or control status, and the level of adducts (below or above the median value) was stronger in subjects who consumed less than one portion of vegetables per d (OR 7.80; $95 \%$ CI $3 \cdot 0,20 \cdot 3)$ than in heavy consumers (OR 4.98 for consumers of two portions per d; OR 1.97 for consumers of three or more portions per d). In another study among healthy subjects, inverse associations emerged between levels of bulky DNA adducts and plasma retinol $(P=0.02), \quad \alpha$-tocopherol $\quad(P=0.04) \quad$ and $\quad \gamma$-tocopherol $(P=0.03)$, but not carotenoids (except a borderline inverse association with $\beta$-carotene; $P=0 \cdot 08)^{(27)}$

Concerning 4-ABP adducts, in a previous study among bladder cancer patients we found that 4-ABP-DNA adducts in bladder biopsies were inversely related to fruit and vegetable intake ${ }^{(20)}$. In a more recent study we reported an inverse correlation also between $4-\mathrm{ABP}-\mathrm{Hb}$ adduct levels and fruit and vegetable consumption in non-smokers ${ }^{(24)}$. Moreover, 4-ABP-Hb adducts were reportedly modulated by the intake of carotenoids in the control population of a large case-control study on smoking-related bladder cancer, this effect being confined to current smokers ${ }^{(28)}$.

Possible mechanisms for the inverse association between fibre intake and adduct formation include:

(1) Bacterial fermentation of dietary fibre produces SCFA, including butyrate, that can protect the colonic mucosa barrier $^{(29)}$, increase apoptotic response to genotoxic carcinogens ${ }^{(30)}$ and enhance glutathione transferase $\pi$ expression $^{(31)}$;

(2) Dietary fibre can decrease the levels of DNA damage by enhancing the action of antioxidant components contained in phytochemicals; the protective effects may be mainly due to some components, including phenolic polysaccharides and polyphenols, which are present in the cell walls of various plants and that can be released by bacterial enzymes in the colon. Indeed, flavonoids, polyphenols and other plant compounds have been shown to be capable of inhibiting DNA adduct formation ${ }^{(32,33)}$, possibly by their antioxidant activity or by interfering with the metabolic pathways of activation/detoxification of food mutagens $^{(33)}$

(3) The protective effects of an increased intake of fibre may be related to increased faecal bulk or reduced transit time ${ }^{(34)}$, thereby diluting potential toxins and carcinogens and reducing their contact time with the colonic epithelium.

It is unlikely that the present results can be explained by bias or confounding. The study had a prospective nature, and dietary ascertainment took place several years before adduct measurement, which was blind as to dietary variables. Alcohol and several of the potential confounding factors, such as age, sex, smoking status, BMI, energy intake, intake of fruit, legumes, vegetables, meat, vitamins and folate have also been evaluated in the present study.

In summary, after finding a clear protective effect of fibres in colon carcinogenesis ${ }^{(35)}$, the present study from the same population (the EPIC prospective study) suggests that fibres can modify the levels of bulky DNA adducts and 4-ABP-Hb adducts.

\section{Acknowledgements}

We are grateful to Julie Britton for comments on the manuscript. 
This paper was made possible by a grant of the European Community (5th Framework Programme) to P. V. (grant QLK4-CT-1999-00 927) and a grant of the Compagnia di San Paolo to the ISI Foundation. All authors are independent from funders. Mortality data for the Netherlands were obtained from Statistics Netherlands.

Also, the work described in the paper was carried out with the financial support of: Europe Against Cancer Program of the European Commission (SANCO); ISCIII, Red de Centros RCESP, C03/09; Deutsche Krebshilfe; Deutsches Krebsforschungszentrum; German Federal Ministry of Education and Research; Danish Cancer Society; Health Research Fund (FIS) of the Spanish Ministry of Health; Spanish Regional Governments of Andalucia, Asturias, Basque Country, Murcia and Navarra; Cancer Research UK; Medical Research Council, UK; Stroke Association, UK; British Heart Foundation; Department of Health, UK; Food Standards Agency, UK; Wellcome Trust, UK; Greek Ministry of Health; Greek Ministry of Education; Italian Association for Research on Cancer (AIRC); Italian National Research Council; Dutch Ministry of Public Health, Welfare and Sports; World Cancer Research Fund; Swedish Cancer Society; Swedish Scientific Council; Regional Government of Skåne, Sweden; Norwegian Cancer Society; Research Council of Norway.

There are no conflicts of interests to declare.

Individual authors' contributions were: M. P. and A. M. performed the analysis of DNA adducts; L. A. and A. C. analysed $\mathrm{Hb}$ adducts; F. V. performed the statistical analyses; K. O., O. R.-N., F. C.-C., J. L., H. B., A. T., D. P., V. K., R. T., S. P., B. H. B.-D.-M., P. H. P., M. K., A. A., C. Martinez, M. D., A. B., M. J. T., J. R. Q., G. B., L. J., B. J., N. E. D., T. J. K., R. S., R. K. and S. B. collected the data in the local EPIC centres; H. A., A. D., S. G., E. G., C. Malaveille and G. M. were part of the working group that performed laboratory analyses in GenAir and contributed to the interpretation of the results; E. R. is the EPIC coordinator; P. V. coordinated the GenAir investigation and wrote the manuscript with $\mathrm{M}$. P. and L. A.

\section{References}

1. Guilbert JJ (2003) The world health report 2002 - reducing risks, promoting healthy life. Educ Health (Abingdon) 16, 230.

2. Krauss RM, Eckel RH, Howard B, et al. (2000) AHA Dietary Guidelines: revision 2000: a statement for healthcare professionals from the Nutrition Committee of the American Heart Association. Stroke 31, 2751-2766.

3. Byers T, Nestle M, McTiernan A, Doyle C, Currie-Williams A, Gansler T \& Thun M (2002) American Cancer Society guidelines on nutrition and physical activity for cancer prevention: reducing the risk of cancer with healthy food choices and physical activity. CA Cancer J Clin 52, 92-119.

4. Key TJ, Allen NE, Spencer EA \& Travis RC (2002) The effect of diet on risk of cancer. Lancet 360, 861-868.

5. Jakszyn P, Agudo A, Ibanez R, Garcia-Closas R, Pera G, Amiano P \& Gonzalez CA (2004) Development of a food database of nitrosamines, heterocyclic amines, and polycyclic aromatic hydrocarbons. J Nutr 134, 2011-2014.

6. Bostrom CE, Gerde P, Hanberg A, Jernström B, Johansson C, Kyrklund T, Rannug A, Törnqvist M, Victorin K \& Westerholm R R (2002) Cancer risk assessment, indicators, and guidelines for polycyclic aromatic hydrocarbons in the ambient air. Environ Health Perspect 110, Suppl. 3, 451-488.
7. Phillips DH (1999) Polycyclic aromatic hydrocarbons in the diet. Mutat Res 443, 139-147.

8. International Agency for Research on Cancer (1983) Polynuclear Aromatic Compounds, Part 1, Chemical, Environment and Experimental Data. ARC Monographs on the Evaluation of the Carcinogenic Risks to Humans no. 32, pp. 1-453. Lyon, France: IARC Press.

9. Giovannucci E, Rimm EB, Stampfer MJ, Colditz GA, Ascherio A \& Willett WC (1994) Intake of fat, meat, and fiber in relation to risk of colon cancer in men. Cancer Res 54, 2390-2397.

10. Probst-Hensch NM, Sinha R, Longnecker MP, Witte JS, Ingles SA, Frankl HD, Lee ER \& Haile RW (1997) Meat preparation and colorectal adenomas in a large sigmoidoscopy-based casecontrol study in California (United States). Cancer Causes Control 8, 175-183.

11. Alexandrov K, Rojas M, Kadlubar FF, Lang NP \& Bartsch H (1996) Evidence of anti-benzo[ $a]$ pyrene diolepoxide-DNA adduct formation in human colon mucosa. Carcinogenesis 17, 2081-2083.

12. Pfohl-Leszkowicz A, Grosse Y, Carriere V, Cugnenc PH, Berger A, Carnot F, Beaune P \& de Waziers I (1995) High levels of DNA adducts in human colon are associated with colorectal cancer. Cancer Res 55, 5611-5616.

13. International Agency for Research on Cancer (1987) Overall Evaluations of Carcinogenicity: An Updating of IARC Monographs Volumes 1 to 42. IARC Monographs on the Evaluation of the Carcinogenic Risks to Humans Supplement, pp. 1-440. Lyon, France: IARC Press.

14. International Agency for Research on Cancer (2004) Tobacco Smoke and Involuntary Smoking. IARC Monographs on the Evaluation of Carcinogenic Risks to Humans, pp. 1-1438. Lyon, France: IARC Press.

15. Ning S \& Xiaobai X (1997) Reductive metabolism of 4-nitrobiphenyl by rat liver fraction. Carcinogenesis 18, 1233-1240.

16. Chiang TA, Pei-Fen W, Ying LS, Wang LF \& Ko YC (1999) Mutagenicity and aromatic amine content of fumes from heated cooking oils produced in Taiwan. Food Chem Toxicol 37, 125-134.

17. Turesky RJ, Freeman JP, Holland RD, Nestorick DM, Miller DW, Ratnasinghe DL \& Kadlubar FF (2003) Identification of aminobiphenyl derivatives in commercial hair dyes. Chem Res Toxicol 16, 1162-1173.

18. Hecht SS (2004) Carcinogen derived biomarkers: applications in studies of human exposure to secondhand tobacco smoke. Tob Control 13, Suppl. 1, i48-i56.

19. Peluso M, Airoldi L, Magagnotti C, Fiorini L, Munnia A, Hautefeuille A, Malaveille C \& Vineis P (2000) White blood cell DNA adducts and fruit and vegetable consumption in bladder cancer. Carcinogenesis 21, 183-187.

20. Airoldi L, Orsi F, Magagnotti C, Coda R, Randone D, Casetta G, Peluso M, Hautefeuille A, Malaveille C \& Vineis P (2002) Determinants of 4-aminobiphenyl-DNA adducts in bladder cancer biopsies. Carcinogenesis 23, 861-866.

21. Palli D, Masala G, Vineis P, et al. (2003) Biomarkers of dietary intake of micronutrients modulate DNA adduct levels in healthy adults. Carcinogenesis 24, 739-746.

22. Bingham S \& Riboli E (2004) Diet and cancer the European Prospective Investigation into Cancer and Nutrition. Nat Rev Cancer 4, 206-215.

23. Peluso M, Munnia A, Hoek G, et al. (2005) DNA adducts and lung cancer risk: a prospective study. Cancer Res 65, 8042-8048.

24. Airoldi L, Vineis P, Colombi A, et al. (2005) 4-Aminobiphenylhemoglobin adducts and risk of smoking-related disease in never smokers and former smokers in the European Prospective Investigation into Cancer and Nutrition prospective study. Cancer Epidemiol Biomarkers Prev 14, 2118-2124. 
25. Vineis P, Hoek G, Krzyzanowski M, et al. (2006) Air pollution and risk of lung cancer in a prospective study in Europe. Int $J$ Cancer 119, 169-174.

26. Guarrera S, Sacerdote C, Fiorini L, et al. (2007) Expression of DNA repair and metabolic genes in response to a flavonoid-rich diet. Br J Nutr 98, 525-533.

27. Mooney LA, Bell DA, Santella RM, et al. (1997) Contribution of genetic and nutritional factors to DNA damage in heavy smokers. Carcinogenesis 18, 503-509.

28. Castelao JE, Yuan JM, Gago-Dominguez M, et al. (2004) Carotenoids/vitamin $\mathrm{C}$ and smoking-related bladder cancer. Int $J$ Cancer 110, 417-423.

29. Toden S, Bird AR, Topping DL \& Conlon MA (2006) Resistant starch prevents colonic DNA damage induced by high dietary cooked red meat or casein in rats. Cancer Biol Ther 5, 267-272.

30. Le Leu RK, Brown IL, Hu Y \& Young GP (2003) Effect of resistant starch on genotoxin-induced apoptosis, colonic epithelium, and lumenal contents in rats. Carcinogenesis 24, $1347-1352$.
31. Treptow-van Lishaut S, Rechkemmer G, Rowland IR, Dolara P \& Pool-Zobel BL (1999) The carbohydrate crystalean and colonic microflora modulate expression of glutathione $S$-transferase subunits in colon of rats. Eur J Nutr 38, 76-83.

32. Rho KA \& Kim MK (2006) Effects of different grape formulations on antioxidative capacity, lipid peroxidation and oxidative DNA damage in aged rats. J Nutr Sci Vitaminol (Tokyo) 52, 33-46.

33. Malaveille C, Hautefeuille A, Pignatelli B, Talaska G, Vineis P \& Bartsch H (1996) Dietary phenolics as anti-mutagens and inhibitors of tobacco-related DNA adduction in the urothelium of smokers. Carcinogenesis 17, 2193-2200.

34. Cummings JH, Bingham SA, Heaton KW \& Eastwood MA (1992) Fecal weight, colon cancer risk and dietary intake of nonstarch polysaccharides (dietary fiber). Gastroenterology 103, 1783-1789.

35. Bingham SA, Day NE, Luben R, et al. (2003) Dietary fibre in food and protection against colorectal cancer in the European Prospective Investigation into Cancer and Nutrition (EPIC): an observational study. Lancet 361, 1496-1501. 